\title{
Lessons from the Strukturwandel in the Ruhrgebiet: turning Northern Greece into an industrial champion?
}

\section{Ansgar Belke ${ }^{1,2,3} \cdot$ Nicos Christodoulakis ${ }^{4} \cdot$ Daniel Gros $^{3}$}

Published online: 4 June 2019

(C) The Author(s) 2019

\begin{abstract}
Against the background of the (at least partially) successfully overcome structural change in the Ruhrgebiet, this project analyses whether and to what extent Northern Greece, especially Central Macedonia with the city of Thessaloniki, can learn from the Ruhrgebiet when conducting the required structural reforms and coping with structural change. In the Ruhrgebiet, the process of structural change seems to be almost complete. More than half of the workforce is now employed in the service sector and that proportion continues to increase. But some problems such as a high proportion of educationally disadvantaged households with a migration background remain due to the missed structural change in the 1960s. This study thus analyses the structural characteristics of the Greek economy and workforce with particular emphasis on the northern regions in Greece and compares them to the Ruhrgebiet and NRW.
\end{abstract}

Keywords International competitiveness · Greece - Education - Employment - Innovation · Ruhrgebiet $\cdot$ Structural change $\cdot$ Trade

JEL classification $\mathrm{F} 16 \cdot \mathrm{I} 25 \cdot \mathrm{I} 28 \cdot \mathrm{L} 16$

\section{Introduction}

The consequences of the debt crisis in Greece and the front-loaded fiscal adjustment that followed seem to be more pernicious and far-reaching than initially expected. Thus far, the country has experienced the deepest recession ever afflicting a European nation

Ansgar Belke

ansgar.belke@uni-due.de

1 King's College London, London, UK

2 University of Duisburg-Essen, Essen, Germany

3 Centre for European Policy Studies, Brussels, Belgium

4 Athens University of Economics \& Business, Athens, Greece 
in the postwar era: output and employment in 2015 had fallen by 15-20\%, relative to their levels in 2010, causing extensive social deprivation and political turmoil. ${ }^{1}$ An equally threatening - though hardly discussed - consequence of the recession is the massive fall in overall investment activity, which has caused a reduction in net capital stock by $6.3 \%$ in real terms relative to its 2010 level, an event unprecedented in non-war times. ${ }^{2}$

In fact, the steep fall in investment is mirrored by a steep rise in unemployment. Figure 1 shows that gross fixed capital formation in Greece had collapsed to just $13 \%$ of GDP, below half the level before the crisis, while unemployment followed a symmetric explosion: Though recently it partially improved thanks to short-term employment programs, in 2014 it was running at around $25 \%$ of the workforce, more than three times higher than before the crisis.

The collapse in investment characterizes both the private and the public sector, as displayed in Fig. 2. Private sector gross capital formation declined to slightly over $10 \%$ of GDP in 2014, while recently public investment somewhat recovered due to higher utilization of European Structural Funds (ESF).

The relationship between underinvestment and unemployment has been extensively researched in the economics literature (Belke and Dreger 2011). The main finding is that restoring employment and economic activity necessitates and, at the same time, encourages, a revival of investment activity. ${ }^{3}$ In many studies, the massive fall in investment activity is found to be both a result of, and a cause for, the sharp decline in output and employment.

The debate becomes more relevant in light of a major initiative recently approved by the European Commission. The 'Juncker package' - named after the current EU President - aims to mobilize private as well as public funds through the European Investment Bank to the tune of Euro 300 billion in order to finance investment projects in the EU. The initiative could not have been timelier for Greece and other debt-stricken economies. Greece should participate in the opportunities that lay ahead by organizing a coherent investment plan. In combination with existing Structural Funds, the new initiative can provide further funding and strategic support in enhancing competitiveness and promoting export capacity of, and job creation in, the Greek economy.

The medium to long-term consequences of underinvestment are significant, not least for the remaining manufacturing basis in Greece. It is, therefore, crucial to examine how other areas in Europe managed to exit from similar crises in the past, so as to set a realistic policy agenda for boosting the economy back on a growth and investment trajectory. A striking such example is the Ruhrgebiet - or the Ruhr district - a highly urbanised area in North Rhine-Westphalia (NRW), Germany. ${ }^{4}$ It experienced a serious structural crisis in the 1960 s, but responded, starting in the 1970 s, with a multifaceted

\footnotetext{
${ }^{1}$ That was on top of the contraction by another $-8 \%$ during 2008-2010 as a result of the global crisis.

${ }^{2}$ At the same time, Portugal's stock decreased by $-3 \%$, while Ireland's rose by $5 \%$. Data are from Ameco; series OKND.

${ }^{3}$ For example, Rowthorn (1999a and 1999b) showed that weaker investment activity is associated with higher unemployment and a fall in wage share; Alexiou and Pitelis (2003) found that the unemployment in 13 economies in the European Union is significantly affected by the process of capital accumulation; Karanassou et al. (2008) found strong empirical support for the investment impact on unemployment in Denmark, Sweden and Finland. Recently, Christodoulakis (2014) has employed a Diamond model with job market frictions to estimate the relationship between capital formation and unemployment in the Euro Area.

${ }^{4}$ The Ruhrgebiet does not correspond to any formal administrative region. It is the name given to a tightly integrated group of cities and other communes which straddle three regions or Bezirke of NRW, namely Düsseldorf, Münster and Arnsberg.
} 


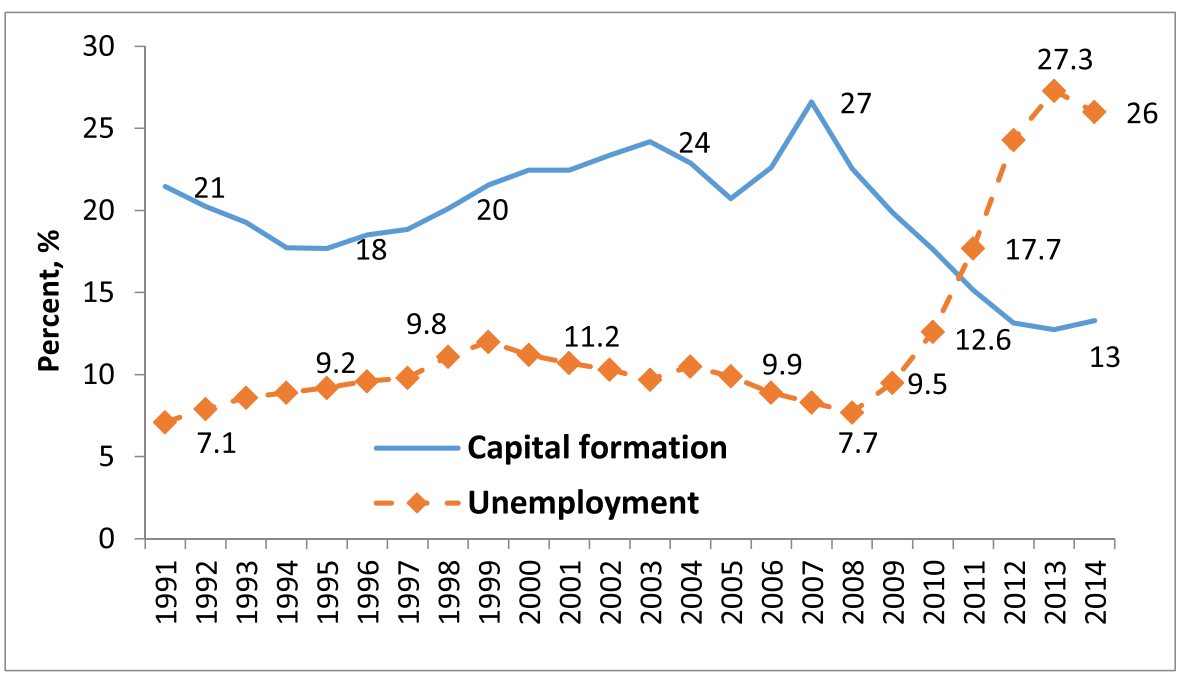

Fig. 1 Gross fixed capital formation and unemployment rate in Greece. Investment is expressed as a percent of GDP. Source: AMECO Database. Series: ZUTN and UIGT respectively

restructuring. The crisis was gradually overcome by shifting the structure of the economy from a focus on coal mining and ancillary industries to a broader base, including services and more high-value added manufacturing (Bauer et al. 2011). This shift was made possible by a radical upgrading of the educational levels of the population.

In order to understand the nature of NRW crisis back in the $1960 \mathrm{~s}$, it is important to note that in the late coal and steel era no further innovations (new products, branches, markets or forms of organisations) have contributed to further growth of the regional economy. One important and often cited reason for this was the so called "education blocking". Up to 1964, no university was located in an area comprising no less than 5.4

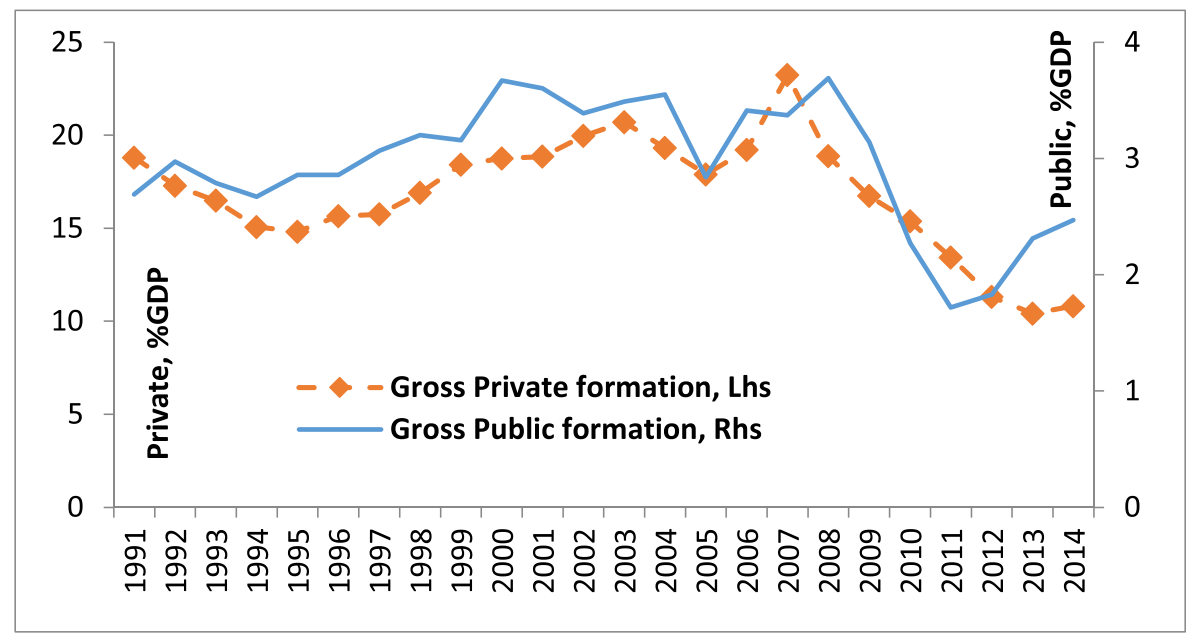

Fig. 2 Gross fixed capital formation of general Government and private sector, as a percent of GDP. Source: AMECO Database. Series: UIGG and UIGP respectively 
million inhabitants. Since the Bismarck period universities and students have been considered as sources of unrest and prefered to be kept away from Germany's "economic heart". 5 Most of the employees in mining possessed a rather low education level ("8. Klasse Abschluss und keine Lehre"). For the simple jobs in the mining industry this proved to be sufficient. ${ }^{6}$ In the 1970 s and 1980 s, when a number of universities had been founded, a labour market for the qualified, pressingly needed for the structural change, gradually developed. ${ }^{7}$ The lost ability of innovation could be traced back to the mono-structure of the coal and steel industry which requested highly specialised suppliers in terms of the amounts and the qualities of the materials, machines and services to be delivered. Since these suppliers did not have an incentive to improve and to innovate, the ability of innovation could not be developed to a sufficient extent in the small and medium-sized firms which were considered to be the driving forces of structural change. Seen on the whole, thus, growth impulses were missing until the $1970 \mathrm{~s}^{8}$

So what reforms took place in the Ruhrgebiet as a reaction to the crisis? The immediate reactions of the economic and political actors were rather defensive. The latter intended to stay with the old structure. Instead of adapting to new market conditions, politicians demanded securing the coal markets through contracts with domestic electricity producers and the limitation of oil and coal imports through tariffs and quotas. By this strategy of ,waiting and pretending“ an immediate structural change after the crisis was missed. Moreover, all over the years the local transit system, the configuration of the leisure areas and the landscape maintenance had been neglected. Hence, it became clear that market-based measures alone could not solve the structural problems. Hence, the government took the responsibility and modernisation of the region with an extensive development programme. ${ }^{9}$

The so-called "Entwicklungsprogramm Ruhr, 1968" was the first step away from a passive crisis management towards a targeted transformation of the Ruhrgebiet. The programme provided the settlement of growth industries and streamlining measures. ${ }^{10}$ In the 1980 s the change in the Ruhrgebiet was felt significantly. Many small- and medium-sized firms located themselves in the region (for instance, in the areas of biotech and environmental techniques) and invested significantly in R\&D. In the 1990 s, the period of the first internet boom, numerous internet firms and telecommunication suppliers were founded. Modernisation and innovations were decisively amplified by the erection of six universities and many technology centres as well as the establishment of the so-called ZIM ("Zukunftsinitiative Montanunion"). ${ }^{11}$ Accordingly, German politics did in the end not allow regional disparities in the education sector to exist permanently.

In the Ruhrgebiet structural change thus took place in the last decades away from mining and industry towards the services sector - just the other way round as it has been

\footnotetext{
${ }^{5}$ See http://www.ruhrgebiet-regionalkunde.de/vertiefungsseiten/the_era_of_coal_and_steel_industry.php.

${ }^{6}$ See https://www.klett.de/alias/1010480

${ }^{7}$ The first university in the „Ruhrgebiet"was erected in 1965 in Bochum.

${ }^{8}$ See http://www.ruhrgebiet-regionalkunde.de/vertiefungsseiten/ the_era_of_coal_and_steel_industry.php.

${ }^{9}$ See https://www.klett.de/alias/1010480.

${ }^{10}$ The latter were started by the establishment of the RAG (Ruhrkohle AG).

${ }^{11}$ See https://www.klett.de/alias/1010480.
} 
requested by the Troika for Greece. ${ }^{12}$ This means that the Ruhrgebiet is not exactly an Industrial Champion but hosts more and more hidden champions on the world markets.

A useful - though smaller and less developed - analogy in Greece that constitutes a comparison to the Ruhrgebiet is the constellation of four regions in the northern part of the country, namely those of Thessaly, Central, West, and Eastern Macedonia including Thrace; grouped together in the present study as 'Northern Greece'. This area, especially Central Macedonia with the second largest city in Greece, Thessaloniki, represents one of the few remaining manufacturing centres in the country, and its role in the Greek economy is said to resemble that of the Land NRW within the German economy. Moreover, Northern Greece is home to important energy resources, as is also the case in NRW. Lignite dominates power generation in Greece (as in NRW), but its contribution to the regional and local economy seems rather limited, both in NRW and in Greece.

Our project therefore looks at the regional level (Belke and Heine 2002, 2006) and seeks to compare the Ruhr district in Germany with the four regions in Northern Greece, asking whether there are lessons which the latter can draw from the former. Put otherwise, does the successful experience of the Ruhrgebiet offer a blueprint for sectoral innovation in Northern Greece?

This paper will thus seek to analyse the structural characteristics of the Greek economy and workforce with a particular emphasis being placed on the northern regions in Greece. We will then proceed to compare these to the Ruhrgebiet district in specific and to NRW more generally. As far as we know, we are the first who conduct such a regional comparison and cannot indicate the methods that are used in the literature to perform this comparison (and our case study method can be related to).

We do not wish to suggest that the problems of Greece today and those of the Ruhrgebiet forty years ago were the same. The Ruhrgebiet represented a regional adjustment problem for Germany, whereas Greece clearly faces a national macroeconomic problem. However, a comparison of the different regional adjustment paths are still interesting. The Ruhrgebiet also had to undertake the adjustment during the 1970s, which were a difficult period for Germany as well given the oil price shock of 1973. Moreover, Greece is the only program where the adjustment is so far still at the beginning whereas Ireland, Spain and, to some extent, Portugal, have left the crisis behind them.

The key findings are first of all that there are some noticeable similarities in the problems both areas face. To illustrate, the qualifications of the workforce show a high degree of similarities. There are also notable differences, in particular the importance of industry and manufacturing, the weight of which in the local economy was excessive in the Ruhrgebiet, but appears lower in Greece. Moreover, it appears that Greece seems to have made considerable progress in tertiary education, at least in quantitative terms. The proportion of the workforce with a university degree is now about the same in Germany and Greece.

But the results in terms of productivity and innovation are very different. It remains to be seen whether this is due to the quality of the university education or the fact that the universities in Greece constitute 'cathedrals in the desert' because there is no high value-added manufacturing base around them to make use of the graduates. The absence of a local manufacturing base could be due to the fact that the middle level

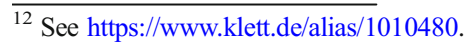


in terms of educational qualifications is much thinner in Greece (and in particular in the north of the country) where the proportion of the workforce without complete upper secondary education is still very large.

The remainder of the present paper is organized as follows: Section 2 describes some key characteristics of Northern Greece within the evolution of the overall Greek economy. Section 3 compares the regional structures of NRW and Northern Greece and points to similarities and differences between the two. Section 4 investigates the two regional labour markets and in particular the characteristics of youth unemployment. Section 5 discusses the importance of human capital on value-added activities, while Section 6 describes the innovation structures in NRW and Northern Greece. Finally, Section 7 argues on the importance of governance in improving local performance. Section 8 finally concludes.

\section{The situation in northern Greece}

In looking on how investment can be accelerated, Greece should at the same time prioritize some sectors which have a greater potential in delivering growth and competitiveness, so as to enhance export capacity and job creation. To this effect, restructuring and renovating the Greek industrial sector should be a priority for reasons that are explained below.

\subsection{The role of manufacturing investment}

Industrial production in Greece faces a long period of stagnation and decline. As displayed in Fig. 3, the industry sector in the 1990s was growing at virtually the same

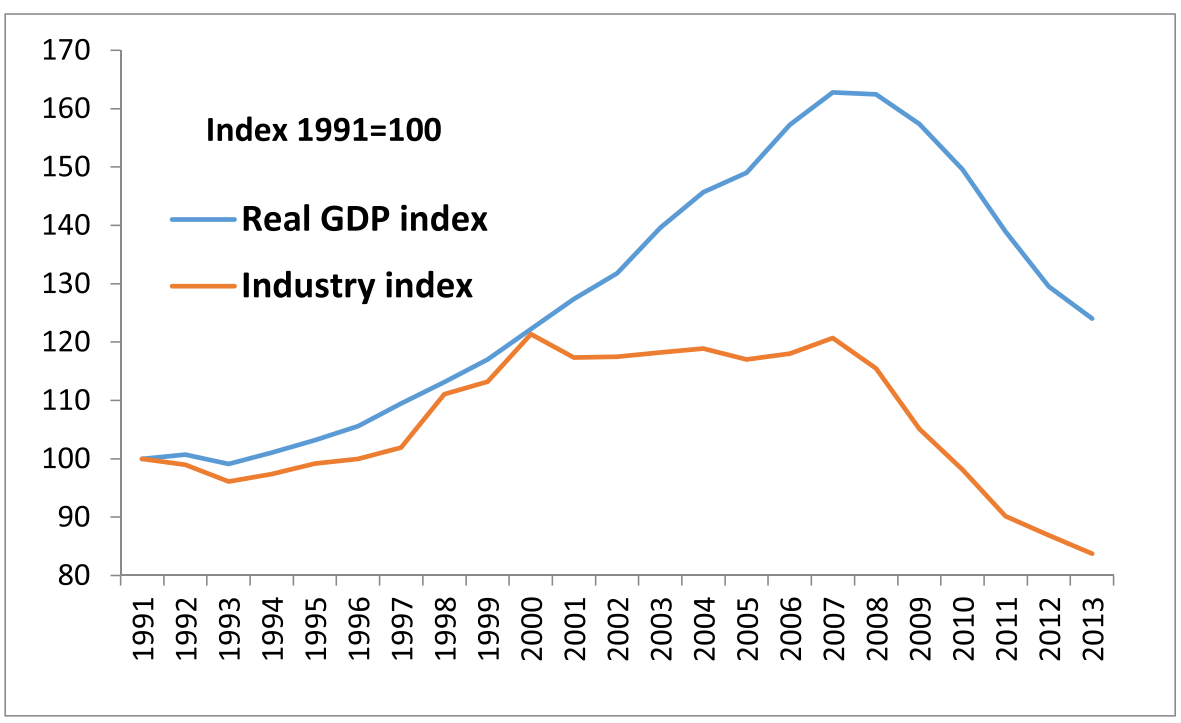

Fig. 3 Industrial production and GDP. The index takes a value of 100 at 1991. Source: AMECO Database. Industrial production: construction excluded (VPRI) 
rate as overall economic activity, but the process was halted in the aftermath of entering the Economic and Monetary Union in 2000.

On the eve of joining EMU in 2000, two effects were set in motion: on the one hand, manufacturing investment benefited from the reduction in the cost of money in the late 1990s and initially rose from the anemic levels at the beginning of the decade. On the other, unit labour costs in manufacturing also rose and eventually hit competitiveness. This further accelerated the reallocation of Greek companies to neighboring Balkan countries, and investment in manufacturing started to decline, as shown in Fig. 4. As a result, industrial activity stagnated despite a strong GDP expansion.

The situation was further aggravated by the 2008 crisis, during which the Greek industry was hit to an extent much stronger than overall activity. Whereas overall activity declined by $-24 \%$ during 2008-2013, industrial activity declined further by a sheer $-31 \%$. At least partly, this can be attributed to the collapse of investment activity. Figure 5 reveals a strong correlation between industrial activity and investment in manufacturing. In 2013, gross fixed capital formation in metals and machinery had fallen below $3 \%$ of GDP, the same level it had in 1995. Production capacity was severely reduced, and industry was unable to fully exploit the reduction in unit labour costs by $15 \%$ that was implemented as part of the austerity program over the last five years.

As a matter of fact, Greek unit labour costs had increased in the past - and especially so vis a vis Germany - causing significant trade imbalances and deterring an export-led growth. However, this erosion was gradual and cannot be regarded as the single culprit for the stagnation of investment in productive capital. To the point, Palaskas et al. (2013) in a recent survey study for Northern Greece industries have found that the reduction of labour costs was not crucial in leading to technological advancement in the area. Other factors affecting the investment environment, such as the quality of the regulatory framework, the elimination of corruption practices and the overall

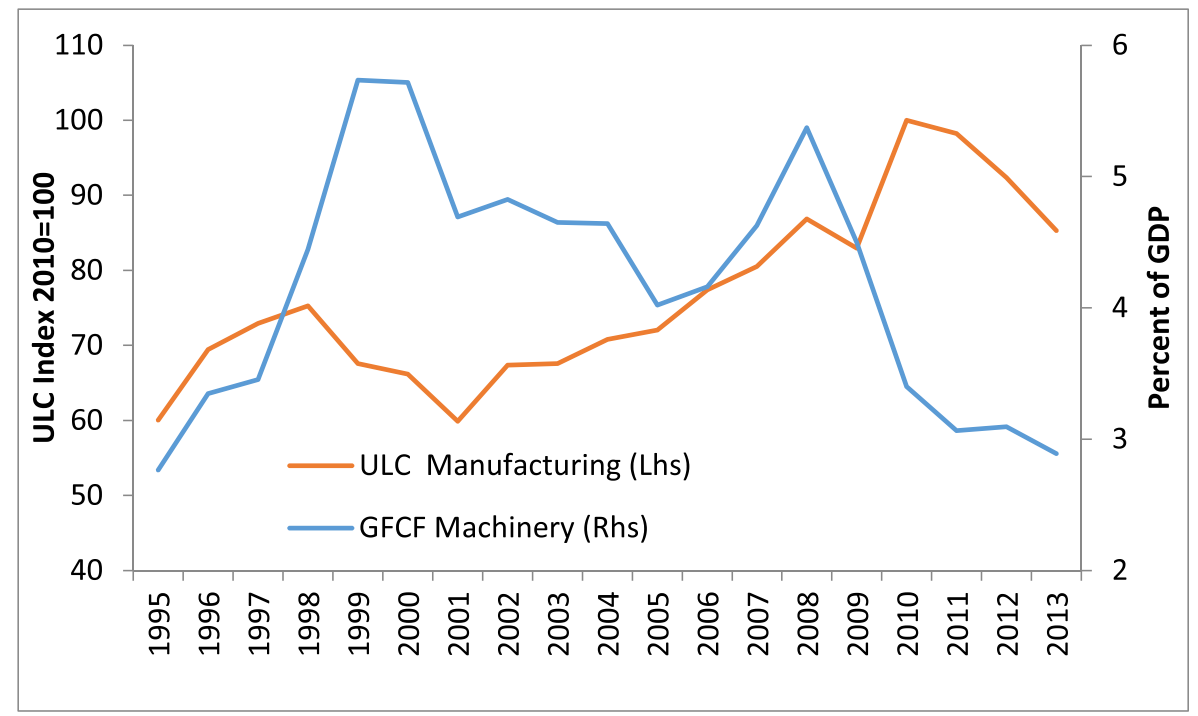

Fig. 4 Unit labour cost in manufacturing (based on hours worked) and gross fixed capital formation in Metal \& Machinery as percent of GDP. ULC index 100 in 2010. Source: AMECO Database. Investment: UIGMA. ECB database for ULC 


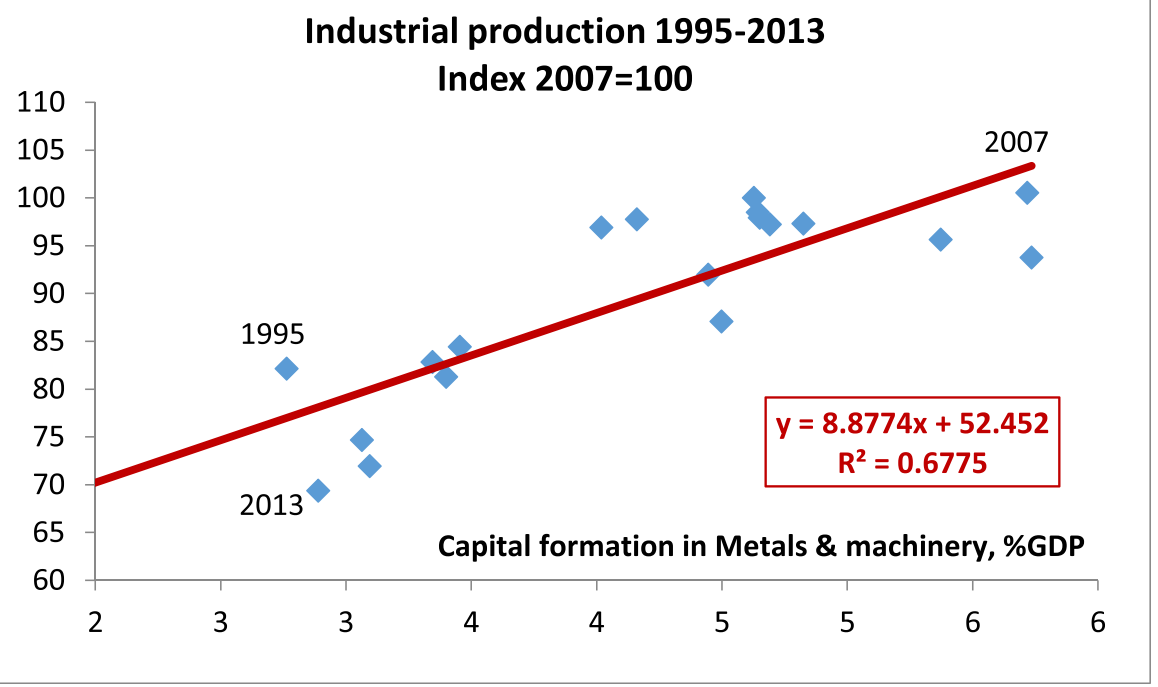

Fig. 5 Industrial production and gross fixed capital formation in Metal \& Machinery. The index takes a value of 100 at 2010. Investments are percent of GDP. Source: AMECO Database. Series: Investment: UIGMA. Industrial production: (construction excluded): VPRI

effectiveness of government might as well have been crucial in shaping productivity and competitiveness as discussed in Section 7 in more detail.

Besides, it is a well-established fact that when new investments are directed mainly to the tradable sectors this leads to substantial productivity improvements and net exports gains. In contrast, investments going mostly into the real-estate sector boost aggregate demand, raise prices, cause the real exchange rate to appreciate and hinder competitiveness.

A clear demonstration of such patterns has been the inability of Greece to attract Foreign Direct Investment in the post-EMU era in order to upgrade technology and expand production. FDI expressed as a percent of GDP hardly improved during the EMU period relative to the 1980 s, while most of the inflows were directed to nonmanufacturing sectors as happened in most economies of the Eurozone periphery. ${ }^{13}$

\subsection{Key economic indicators of northern Greece}

Greece encompasses a total of 13 regions comparable to the 'Länder' in Germany. ${ }^{14}$ Northern Greece is comprised of three geographical areas, namely Macedonia, Thrace and Thessaly, which are administratively structured in four regions out of 13 in the country as a whole: West Macedonia, Central Macedonia, Eastern Macedonia \& Thrace, and Thessaly. The latter was historically

\footnotetext{
${ }^{13}$ A study by Christodoulakis and Sarantides (2015) shows that the differences in composition and volumes of FDI explain the diverging patterns of external balances in the Eurozone countries.

14 Though regions are small compared with the average European size, their number was left untouched by the recent "Kallikratis" reform on decentralized administration. The reform reduced the number of municipalities (from 1.034 to 325), as well as enhancing them by conferring new functions to the regional and local levels and strengthening their role in the formulation and implementation of regional policies.
} 
considered as part of central, rather than northern, Greece but its close economic links with Thessaloniki and the other regions have made it a more integral part of the area in question. Some key characteristics of Northern Greece are displayed in Table 1 and summarized as follows:

At an aggregate level, Northern Greece with $43 \%$ of national land, 33\% of total population and $25 \%$ of Greek GDP represents an area less populous and developed than the rest of the country.

The rate of unemployment in Northern Greece stands consistently higher than the national rate, both before and after the economic crisis, as will be examined in Section 4. The intraregional dispersion of unemployment is found to be very high, between $24 \%$ and $30 \%$, suggesting that there exist labour market enclaves and poor mobility between the prefectures in each region.

Despite the weak demographics, immigration flows are not very strong in Northern Greece. Immigration density is defined as the proportion of foreigners to total population, and in all regions of Northern Greece it appears to be substantially lower than the national average of $8.43 \%$ in 2011. In Eastern and Western Macedonia, densities are in fact below half the national level. In combination with the high dispersion mentioned above, this finding reveals that the unemployment problem has deeper structural characteristics and was not primarily caused by immigration flows. Most probably this is due to the fact that local labour force is not specialized enough so as to leave less skilled job opportunities for outsiders, as examined in Section 5.

Table 1 Key characteristics for the four regions in Northern Greece ${ }^{1}$

\begin{tabular}{|c|c|c|c|c|c|c|}
\hline & $\begin{array}{l}\text { Central } \\
\text { Macedonia }\end{array}$ & $\begin{array}{l}\text { Eastern } \\
\text { Macedonia } \\
\text { \& Thrace }\end{array}$ & $\begin{array}{l}\text { Western } \\
\text { Macedonia }\end{array}$ & Thessaly & Area total & GREECE \\
\hline Area, in $\mathrm{km}^{2}$ & 18,811 & 14,158 & 9451 & 14,037 & 56,457 & 131,957 \\
\hline As $\%$ of total & $14.26 \%$ & $10.73 \%$ & $7.16 \%$ & $10.64 \%$ & $42.78 \%$ & \\
\hline Population 2011, '000 & 1882 & 608 & 284 & 733 & 3507 & 10,815 \\
\hline As $\%$ of total & $17.40 \%$ & $5.62 \%$ & $2.62 \%$ & $6.78 \%$ & $32.42 \%$ & \\
\hline Real GDP, in $2005 €$ bn & 24,201 & 7087 & 4627 & 8533 & 44,448 & 179,625 \\
\hline Regional share $\%$ & $13.47 \%$ & $3.95 \%$ & $2.58 \%$ & $4.75 \%$ & $24.74 \%$ & \\
\hline Immigration density, $\%$ & 6.22 & 3.61 & 4.09 & 6.08 & & 8.43 \\
\hline Industrial Zones ${ }^{2}$ & 4 & 6 & 1 & 4 & 15 & 23 \\
\hline Industrial land $\mathrm{m}^{2}$ & $13,109,311$ & $12,632,856$ & $1,104,009$ & $7,602,483$ & $34,448,659$ & \\
\hline Companies & 811 & 307 & 15 & 243 & 1376 & \\
\hline$\%$ of total & $16.03 \%$ & $34.53 \%$ & $6.67 \%$ & $16.87 \%$ & $20.20 \%$ & \\
\hline Turnover 2013, € mn & 3942 & 879 & 19 & 1119 & 5958 & \\
\hline $\begin{array}{l}\text { Per firm, } \\
€ \mathrm{mn}\end{array}$ & 5.857 & 4.775 & 1.474 & 5.826 & 5.610 & \\
\hline
\end{tabular}

${ }^{1}$ ELSTAT, Greek Statistical Service. Regional Tables, unless otherwise stated

${ }^{2}$ ETVA. Note: Company data for the Kilkis prefecture not available. The turnover of the industrial area in Volos A, Thessaly, not available, and is assumed to have the same average per company as in the Volos B area. Reference year is 2014 . 


\subsection{Regional advantages}

Though treated here as one area, it is crucial to note beforehand that Northern Greece is still far from being a homogeneous structure, economically or otherwise. The four regions share some uneasy characteristics of backwardness relative to national levels, but they are quite different in several aspects. Additionally, as a result of poor institutional and market integration, they show a high degree of intraregional disparities. This finding suggests that achieving intraregional and interregional convergence is a crucial prerequisite for making Northern Greece a pivotal area of new industrialization. With this caveat in mind, a number of advantages of Northern Greece in supporting a revival of industrial activity in Greece are described below.

(i) Manufacturing infrastructure: Northern Greece is hosting the majority of industrial infrastructure and a good share of the R\&D capacity of the country: specifically, 15 out of 23 organized Industrial Areas, three out of five SME parks, and 18 out of 63 technology institutes are located in Northern Greece. The main infrastructure is concentrated in Thessaloniki, but some parts are allocated in the other regions as well; details are shown in Table 1.

(ii) resources. A substantial part of mineral stocks are located in Northern Greece and this can provide several opportunities for new production investment and employment. Besides, minerals can be utilized for environmental-cleaning purposes. Synergies with local R\&D can contribute to the creation of modern environmental technologies, which, in turn, can upgrade the quality standards of conventional manufacturing. A detailed description is given by Arvanitidis (1998) and, more recently, by Charalampides et al. (2014).

(iii) Geography: Northern Greece hosts most of the industrial activity in the country. According to Christodoulakis and Petrakos (2000), manufacturing activity during all the postwar period was mostly concentrated along the axis Athens-Thessaloniki, with major branches in Northern Greece, and minor ones in Eastern Greece. After 1989, the industrial geography proved to be a substantial advantage for local industries in developing trade and production links with neighboring Balkan countries.

(iv) Energy hub: Northern Greece is soon expected to upgrade the energy infrastructure. The Trans-Adriatic Pipeline (TAP) is designed to transfer natural gas on ground from Turkey to Albania and then underwater to Italy. From a total length of $850 \mathrm{~km}, 550 \mathrm{~km}$ would pass through the northern part of Greece. This is envisaged to create several new opportunities in construction, manufacturing and the energy sector.

(v) Technology clusters: The growth potential of Northern Greece became evident in the early 1990 s as the restructuring of neighboring Balkan economies generated a multitude of opportunities for trade, investment and new employment flows. The region of Central Macedonia was in 1995-1997 awarded by the European Union with a Regional Technology Plan (RTP), in order to foster innovation and promote productivity in the industrial sector; for a description see Tsipouri (1998). As explained by Komninos (2008), RTP proved quite successful and managed to create strong links between local industries and local technology centers. Similar initiatives were later undertaken for the region of Thessaly and more recently for the poorer regions of Western Macedonia, and Eastern Macedonia and Thrace. 


\section{Regional economic structures compared}

The Ruhrgebiet does not correspond to any formal administrative region. It is the name given to a tightly integrated group of cities and other communes which straddle three regions or Bezirke of NRW, namely Düsseldorf, Münster and Arnsberg. Northern Greece constitutes an important part of the overall Greek economy, much in a similar way as NRW does in Germany. Both geographical entities contribute roughly between one-fifth and one-quarter of total national output. But the economy of northern Greece is small, compared to the major regions of Germany. This applies even more if one looks at sub-units within northern Greece, compared to NRW. For example, Central Macedonia (with the city of Thessaloniki as its main centre) is the largest region in northern Greece, as can be seen in Table 1. Its annual value added is below 30 billion euro, less than one half of Münster, which constitutes the smallest region within NRW. The Bezirk (NUTS 2 region, in the 'Nomenclature for Units in Territorial Statistics) of Düsseldorf alone produces a value added that is almost as large as that of all of Greece.

The three other northern regions in Northern Greece (Eastern and Western Macedonia, and Thessaly) each produce a value added of less than 10 billion euro annually, comparable to medium-sized cities in NRW, or Germany in general. This relatively small size of regional economies in Greece, coupled with the absence of other manufacturing centres in neighbouring countries, means that it would be very difficult for manufacturing to become a key driver of a new growth strategy for northern Greece unless it is restructured and specialised in specific niches sectors.

The Land NRW has reached an income per capita that is very close to the German average. By contrast, northern Greece is considerably less productive than the rest of the country. Table 2 below shows the variations in the regional GDP per capita relative to the respective national average for the year 2011 (latest available data). There are some variations within NRW, with the Bezirk Münster 10\% below the German average and Düsseldorf (Bezirk in the core of the Ruhrgebiet) 12\% above, but the average for NRW is almost exactly equal to the German average.

By contrast the entire northern region of Greece has an income level, which is $23 \%$ below the national average, with the eastern part being considerably poorer and the western part apparently better off. However, as will become clearer later, this higher GDP in Western Macedonia is a statistical artefact resulting from the importance of the lignite mining (and power generating)

Table 2 Regional GDP per capita relative to national average

\begin{tabular}{lllr}
\hline Germany & \multicolumn{3}{c}{ Greece } \\
\hline Nordrhein-Westfalen & 1.01 & Northern Greece & 0.77 \\
Düsseldorf & 1.12 & Eastern Macedonia \& Thrace & 0.71 \\
Köln & 1.05 & Central Macedonia & 0.78 \\
Münster & 0.90 & Western Macedonia & 1.00 \\
Detmold & 0.98 & Thessaly & 0.70 \\
Arnsberg & 0.92 & & \\
\hline
\end{tabular}

Own elaboration on Eurostat data (Regio database). Reference year is 2014 
operations whose value added impacts on the regional value added. Northern Greece thus constitutes one of the poorer parts of a country.

There are also important differences in the structures of both regions. Industry contributes today about one-quarter of value added in NRW (with construction and services accounting for the remainder). The proportion of industry was much higher in the past, when coal mining and associated industries dominated the regional economy. This mono-centric structure led to a serious crisis starting during the 1960s. It seems that the structural change has mostly been accomplished in NRW as the contribution of industry has been rather stable over the last two decades (with some cyclical variations, see below) and the average for NRW is very close to the overall German average. There are only two Bezirke (Detmold and Arnsberg) within NRW where industry is more important, contributing $30 \%$ of overall value added.

Northern Greece is often taken to constitute a regional manufacturing centre. However, the contribution of industry to regional value-added creation is, on average only $16 \%$; which is higher than the Greek average of $12 \%$, but 10 percentage points lower than the value for NRW. Northern Greece is thus more industrialised than the rest of Greece, but much less so than NRW.

Within northern Greece, Western Macedonia constitutes an outlier with industrial value added contributing to over $40 \%$ of the total local economy in 2011 .Over time this has risen to close to $50 \%$, indicating that this region depends almost completely on industry. This elevated value for Western Macedonia is chiefly due to one key industrial activity, namely the large lignite mining and power generation complex around Ptolemais.

Industry comprises both manufacturing and mining. It is not always possible to obtain data separately between these two sub-sectors. But for Greece these data are available at the regional level. If one separates manufacturing from mining (see Table 3 below), a clear picture emerges since the value added created by manufacturing is less than 5\% in Western Macedonia, leaving $45 \%$ to mining. Given that another 5\% is derived from agriculture, one finds a region whose value-added structure resembles more that of an emerging raw material-centred economy than that of the average EU member state.

Manufacturing contributes even less than the Greek average 10\% of GDP and agriculture remains relatively important, in value added terms as well as employment

Table 3 Sectoral contributions to regional value added in northern Greece

\begin{tabular}{lllll}
\hline & $\begin{array}{l}\text { Industry (= manufacturing } \\
\text { plus mining) }\end{array}$ & Manufacturing & Mining & Agriculture \\
\hline EL - Greece & 13.32 & 9.18 & 4.15 & 3.37 \\
EL1 -Northern Greece & 18.51 & 11.48 & 7.04 & 6.11 \\
EL11 - Eastern Macedonia \& Thrace & 15.04 & 11.04 & 4.00 & 6.57 \\
EL12 - Central Macedonia & 14.74 & 12.20 & 2.54 & 5.19 \\
EL13 - Western Macedonia & 49.51 & 4.51 & 45.00 & 4.90 \\
EL14 - Thessaly & 15.29 & 13.58 & 1.71 & 9.00 \\
\hline
\end{tabular}

own elaboration on Eurostat data (Regio database). Reference year is 2014 
levels. This is especially the case in the northern part of the country where its contribution averages about $6 \%$ (in value added terms) and its share of employment is above $10 \%$. Thus, the economy of northern Greece remains characterised by the primary sectors, agriculture and mining, much more than NRW, where agriculture plays only a negligible role.

Except for Western Macedonia there are thus more differences than parallels between Northern Greece and NRW. Only Western Macedonia looks superficially like the Ruhrgebiet during the 1960s in that industry contributes to one half of value added. But this is due to the lignite mining and power generation complex located there.

The large lignite mining operations in Western Macedonia constitute a surprising parallel between NRW and northern Greece. However, it seems that little manufacturing has been spawned by lignite mining, which is usually done in open-cast operations using very large machinery but few workers. In this sense lignite mining seems quite different from underground (black) coal mining. Given that lignite can be used only for power generation purposes, lignite mining does not foster the emergence of a local manufacturing complex.

In NRW the manufacturing complex has sprung up around the (black) coal mines. This was not the case around the lignite deposits and their associated power generation stations, which seem somewhat isolated from the local economy. The reason is that, unlike lignite, (black) coal can be used to make iron and steel, which can then be transformed and processed in a wide variety of sectors.

It is thus not surprising that the economy of Northern Greece depends much less on manufacturing than that of NRW or the Ruhrgebiet in particular. Table 3(above) shows that mining constitutes a relatively important part (7\%) of the local economy. Agriculture and mining together are more important than manufacturing.

Central Macedonia with the city of Thessaloniki has somewhat more manufacturing and relatively less mining and agriculture. But even here, manufacturing contributes only $12 \%$ to the local value-added creation. Construction used to play a relatively important part of the economy during the boom years up to 2008, but its part has shrunk also to less than $4 \%$. This implies that services of various forms contribute over $80 \%$ of local value added. This is higher than the corresponding value for NRW. Superficially the economy of most of northern Greece has thus a more modern economic structure from this point of view.

Unfortunately, no comparable data are available on the split within industry between manufacturing and mining for the regions within NRW.

The data available for the Land NRW shown in Fig. 6 follow an interesting cycle, with the weight of industry falling from 30\% of GDP in 1991 during most of the 1990 s to below $25 \%$ during the recession of 2002-2003. There has since been a partial recovery of industry to about $26 \%$. It is also apparent that mining was already marginal in 1991 (contributing less than 2\% to GDP) and has since become negligible. Agriculture was also already negligible at the beginning of the 1990s. This implies that even 20 years ago the economy of NRW was dominated by services, which accounted already then for about $70 \%$ of GDP.

The low weight of manufacturing in the Greek economy suggests that any increased expenditure in Germany is unlikely to have a noticeable impact on employment in Greece. Apart from agriculture, there is no local base for exports of goods that German 


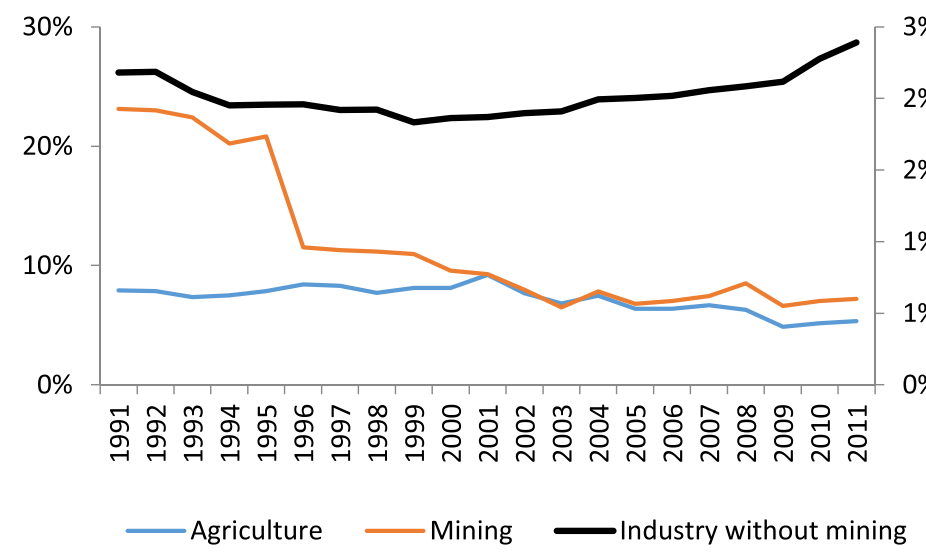

Fig. 6 Sectoral contribution to GDP in NRW. Industry is depicted on the RHS

households or businesses might want to buy. The same is likely to apply to infrastructure investment in Germany, which stimulates directly only the local labour market.

It is remarkable that northern Greece has a higher share of industry and manufacturing than the rest of the country, but income per capita is also lower in the north. This suggests that in Greece manufacturing and mining do not constitute areas where the value added per worker is particularly high. This does not seem to be the case in NRW, where the value added per worker in manufacturing is not lower than in the rest of the economy.

Though it is clear from the above that initial conditions in the Ruhr during the 1970s and present time Greece are substantially different, it is still interesting to utilize the lessons drawn from the industrialization of NRW as a successful transformation process that might be applicable in current Northern Greece in at least two directions:

First, because it shows that for a backward region to be transformed into a champion investment in human skills at both the high and the medium level is an absolute prerequisite.

Second, because it demonstrates how essential is the role that the accumulation of manufacturing activities in certain area as a mechanism to acquire economies of scale and foster an innovation culture.

\section{Regional labour supply and employment}

A first key variable in any structural adjustment process is the regional potential in terms of the quality of the workforce. The overall impression is that the quality of the workforce in Greece, and in particular in its northern regions, is rather low and that the limited potential is underemployed. While the multi-year recession in Greece is a determining factor it is not the single most important explanatory variable. Underlying structural factors that characterize the evolution of the real economy in Greece during the past three decades have to be taken into consideration.

The innovation potential seems limited. Expenditure on innovation, such as R\&D is very low. Nevertheless, the key to a re-launch of the regional economy should be sought rather in the upgrading of skills set of the local work force, rather than trying to 
foster R\&D expenditure as a precondition. The basis for substantially raising expenditure seems to be lacking at present, in particular given fiscal consolidation efforts of the central government, which impact on public investment capacity.

\subsection{Unemployment}

The evolution of unemployment in Greece over the past decade suggests that the problem is ingrained throughout the country, as shown in Table 3, without clear regional patterns. The national unemployment rate was already at $12 \%$ when the country entered the euro in 2000, i.e. higher than the EU or Euro Area average and three percentage points higher than the German average.

By 2009, unemployment in Greece had converged to the EU average. However, this convergence process proved to be fleeting. As shown in Fig. 1, the ensuing sovereign debt and economic crisis led to a tripling of the unemployment rate to over $27 \%$ in early 2013, almost six times the corresponding German level. This level of underutilization of human resources constitutes the key policy challenge for Greece today (Table 4). ${ }^{15}$

Within Germany, the Ruhr area had in the year 2000 a lower unemployment rate than the national average, but this changed over time and by 2013 the unemployment rate throughout the region was slightly above the national average of $5 \%$.

The regional pattern within Greece was different. Unemployment fell in almost all regions as long as the credit financed spending boom lasted and all regions suffered greatly from the severe fiscal adjustment process that followed after 2009. However, there is some regional variation. For example, the region of Thrace went from having the highest unemployment rate to one, which is somewhat below the national average.

However, the degree of regional dispersion within Greece has remained remarkably low given the high average level of registered unemployment since the onset of the crisis. According to Eurostat data (2014), the standard deviation across regions in Greece reached a level of $10.3 \%$ in 2011.However, as Eurostat concludes, "low dispersion should not be interpreted as a positive sign for labour markets per se. In the case of Greece, which has quite small regional disparities in unemployment rates, all NUTS 2 regions recorded high unemployment rates over $14 \%$ in 2011. This shows that dispersion only indicates the disparities between regions and not the overall level of unemployment." ${ }^{16}$ The coefficient of variation, which takes into account the average is, however, much lower.

\subsection{Youth unemployment}

A particular problem for Greece is youth unemployment (Belke 2013). Figure 7 shows the evolution of youth unemployment rates throughout the regions of Northern Greece. There is considerable co-movement among the Greek regions, with the exception of Western Macedonia that stands out with rates even higher than in the rest of Greece. At present the youth unemployment rate is close to $70 \%$ in this region, against a national

\footnotetext{
$\overline{15}$ At the time of writing, November 2014 the latest available unemployment data for Greece is August 2014 when registered joblessness stood at $25.9 \%$. This level was the first time in two years that unemployment declined below the threshold of $26 \%$.

${ }^{16}$ See http://epp.eurostat.ec.europa.eu/statistics_explained/index.php/Regional_labour_market_disparities, October 7 th 2014.
} 
Table 4 Unemployment rates

\begin{tabular}{|c|c|c|c|c|c|c|}
\hline GEO/TIME & 1999 & 2009 & 2010 & 2011 & 2012 & 2013 \\
\hline European Union (28 countries) & & 9.0 & 9.6 & 9.7 & 10.5 & 10.8 \\
\hline Germany & 8.9 & 7.7 & 7.1 & 5.9 & 5.5 & 5.3 \\
\hline Nordrhein-Westfalen & 7.5 & 7.8 & 7.5 & 6.4 & 5.9 & 6.0 \\
\hline Düsseldorf & 7.7 & 7.7 & 7.7 & 6.9 & 6.6 & 6.4 \\
\hline Köln & 6.8 & 7.1 & 7.1 & 6.0 & 5.4 & 5.9 \\
\hline Münster & 7.6 & 7.3 & 6.7 & 5.3 & 5.0 & 5.1 \\
\hline Detmold & 6.4 & 7.7 & 7.1 & 5.6 & 4.8 & 5.1 \\
\hline Arnsberg & 8.3 & 9.2 & 8.4 & 7.3 & 6.9 & 6.8 \\
\hline Greece & 11.9 & 9.6 & 12.7 & 17.9 & 24.4 & 27.3 \\
\hline Eastern Macedonia \& Thrace & 13.0 & 11.1 & 14.5 & 20.2 & 22.8 & 26.8 \\
\hline Central Macedonia & 11.8 & 10.1 & 13.7 & 19.7 & 26.2 & 30.2 \\
\hline Western Macedonia & 14.4 & 12.4 & 15.4 & 23.1 & 29.7 & 31.6 \\
\hline Thessaly & 13.1 & 9.2 & 12.1 & 16.8 & 22.6 & 25.4 \\
\hline
\end{tabular}

European Commission, Regio dataset. Reference year is 2014

average of $49.3 \%$ (August 2014) and only $10 \%$, or one sixth of this level, for NRW. Greek and German levels of youth unemployment are of a completely different magnitude with about $10 \%$ in Germany and generally close to or over $50 \%$ in various parts of Greece.

Moreover, the two countries have followed the opposite path: during the demand boom in the pre-crisis period of 2001-2008, youth unemployment rates declined somewhat in Greece, but increased in Germany. Since the start of the crisis in Greece, unemployment has skyrocketed there, but somewhat fallen in Germany.

One reason why the measured youth unemployment rates are so high in Greece is that only a small part of the young population is economically active (Barslund and

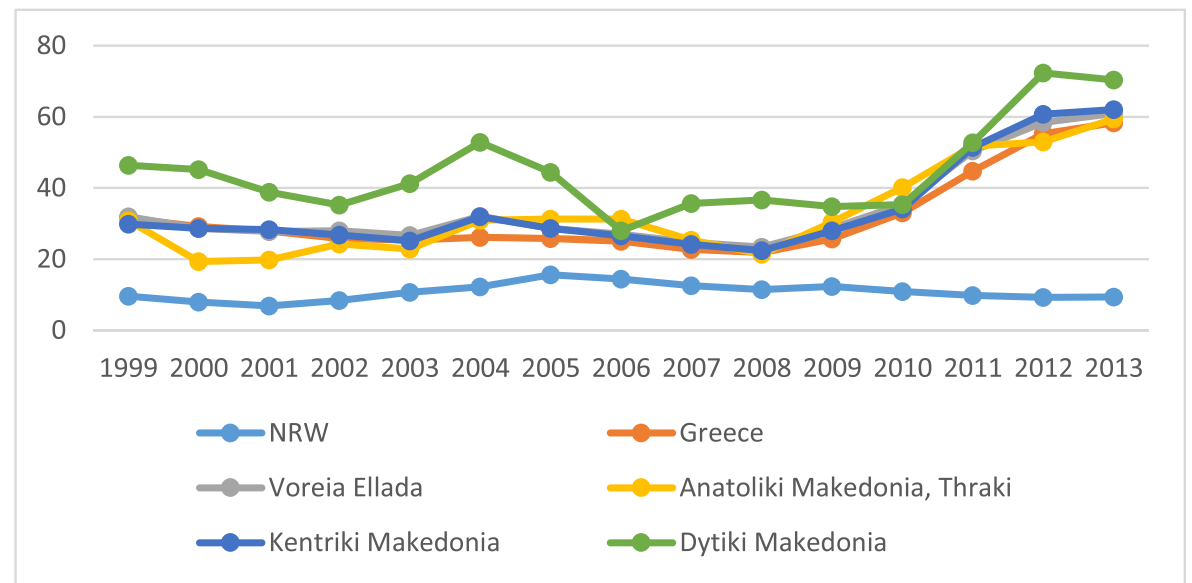

Fig. 7 Youth unemployment in Germany and Greece, 1999-2013. Source: European Commission, Regiodataset 
Table 5 Activity rates of youth (\%)

\begin{tabular}{lllr}
\hline Germany & 50.9 & Greece & 28.4 \\
\hline Nordrhein-Westfalen & 46.1 & Northern Greece & 26.2 \\
Düsseldorf & 45.7 & Eastern Macedonia \& Thrace & 29.6 \\
Köln & 44.1 & Central Macedonia & 24.2 \\
Münster & 49.3 & Western Macedonia & 20.9 \\
Detmold & 47.4 & Thessaly & 30.5 \\
\hline
\end{tabular}

European Commission, Regio dataset. Reference year is 2014

Gros (2013) as shown in the Table 5 below. ${ }^{17}$ In Germany about one half of the young population (15-24) is economically active, but in Greece this proportion is much lower at $28.4 \%$ for the national average. In Northern Greece this percentage is at $26 \%$ somewhat lower though still almost one half of the German value. Western Macedonia constitutes again an outlier with a youth activity rate of only $21 \%$; one of the lowest levels among the 200 NUTS 2 regions in the EU.

An unemployment rate of 50\% among the youth implies that the 'economic activity' of the young in Western Macedonia consists essentially of the young being unemployed, and this obviously discourages many of them to participate in a hopeless search for jobs.

The unemployment rates of $50 \%$ or more observed in Greece thus do not imply that over one half of the young are unemployed. The proportion of the youth looking for a job is measured by the unemployment ratio, i.e. the number of young unemployed relative to the total number of youth. This measure is much lower because, as mentioned, so few Greek youth are looking for a job. Table 6 below compares the unemployment ratios in Germany and Greece.

In Germany only about $4 \%$ of the young cohorts (between 15 and 24 years old) are looking for a job without finding one. In Greece this proportion is almost 4 times higher, with relatively little variation across regions. It seems that beyond a certain level of unemployment the young simply give up looking for a job.

\section{Human capital formation}

One key indicator of the quality of the regional workforce is its level of education.

\subsection{Lack of secondary schooling as an indicator of structural problems}

Modern manufacturing and services require in general at least some secondary educa-

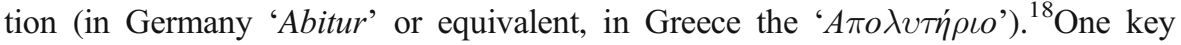
indicator for the problems a region might encounter to develop a competitive economy

\footnotetext{
${ }^{17}$ The unemployment rate is measured by dividing the number of those looking for a job by those economically active (employed plus unemployed).

${ }^{18}$ High school education and degrees in Greece are unified and harmonized nationwide. In difference to Germany, where every Land (region) has authority over education, in Greece the process is centralized by the education ministry in Athens.
} 
Table 6 Unemployment ratios

\begin{tabular}{lllr}
\hline Germany & 4.0 & Greece & 16.6 \\
\hline Nordrhein-Westfalen & 4.3 & Northern Greece & 16.0 \\
Düsseldorf & 4.6 & Eastern Macedonia \& Thrace & 17.6 \\
Köln & 3.8 & Central Macedonia & 15.0 \\
Münster & 4.2 & Western Macedonia & 14.7 \\
Detmold & 4.2 & Thessaly & 17.5 \\
\hline
\end{tabular}

European Commission, Regio dataset. Reference year is 2014

is the proportion of the working age population which has not completed secondary education.

Today the share of this type is only one fourth of the working age population of the EU. For Germany the proportion is considerably lower, at about 14\%.Within Germany the Ruhr area fares much worse, with a share of these undereducated of about $20 \%$, or 6 percentage points higher than the national average.

Greece is clearly in a different league, with a national average level of about $33 \%$ still today. But the country has made important progress, both absolute and relative to the EU average and Germany. In the year 2000 almost $50 \%$ of the Greek workforce did not have secondary education. This was 17 percentage points more than today. The gap with the EU average has thus been considerably narrowed in a little over one half generation.

The reason for this quick progress is that the younger generation in Greece is very different in terms of educational level than the older ones. This difference is much more marked in Greece than in Europe in general and Germany in particular.

Figure 8 shows the proportion of each 5 years cohort (indicated by age limit) that has completed secondary education. This percentage is now close to 90 for the 25-29 year olds in Germany. In Greece it is about 10 percentage points lower. ${ }^{19}$

The differences in educational attainment used to be much higher. For example, among the 50-54 age cohort the difference was over 30 percentage points. For those born during the early 1960s the proportion with a completed secondary education was almost two times higher in Germany (70\%) than in Greece (38\%).

The regional variations in Greece are also rather marked, as shown in Table 7. In the Northern regions the proportion of the undereducated is generally much higher. In 2000, with a national average below $50 \%$, two of the Northern regions had values of $60 \%$. Some regions have been able to reduce the distance to the national average, but Thrace, which had the highest level $(62 \%$ in 2000) has made less progress than others and now is at a level of $50 \%$, worse than the country's average 14 years ago.

The Central Macedonia region with the city of Thessaloniki has always been close to the national average. Western Macedonia seems to be catching up, as its ratio of persons without completed secondary education fell from almost 60 to $42 \%$. Within

\footnotetext{
${ }^{19}$ For comparative purposes, one may consider that Portugal, which had traditionally even lower educational rates, has recently caught up to Greece.
} 


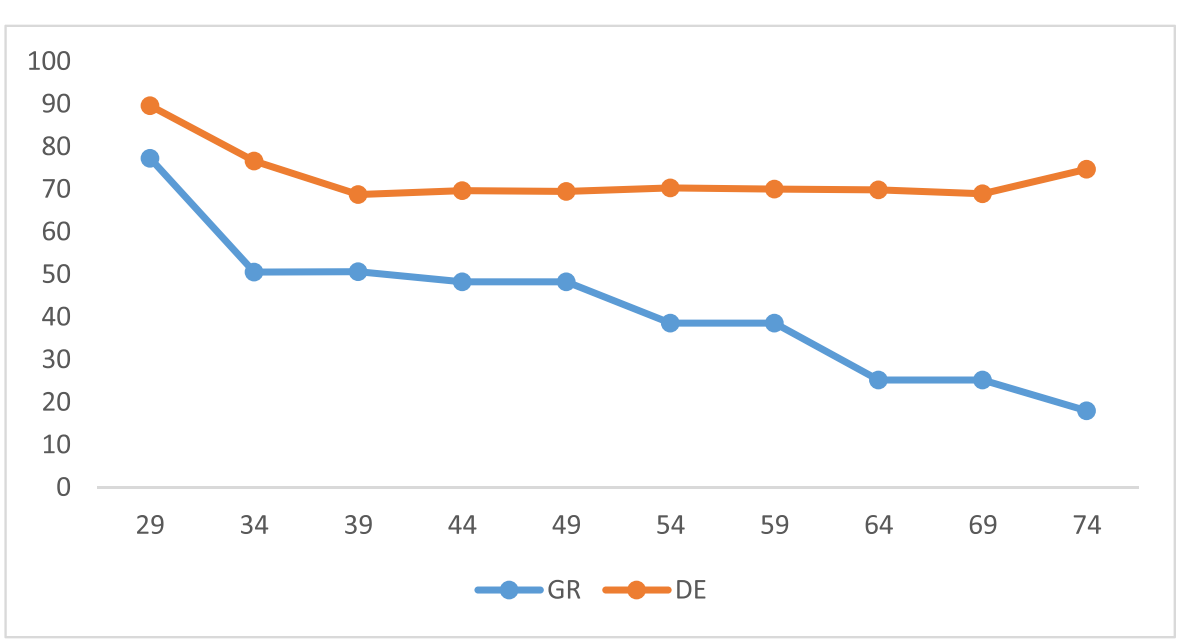

Fig. 8 Proportion of cohort with completed secondary education. Source: Barro Lee dataset

NRW there is much less variation, with all subregions below 20\%, but considerably above the current German national average of below $14 \%$.

In terms of the proportion of the youth without secondary education Greece today, and particularly its northern area appears similar to NRW about 40 years ago. Figure 9 shows for the Land NRW the proportion of early school leavers (those not finishing even Hauptschule in the German system), those who have completed the minimum obligatory schooling (Hauptschule) and those with a completed secondary degree which grants access to University level education.

It is apparent that there has been a complete change since 1970.At the beginning of this period only less than $10 \%$ of all students finished secondary education whereas

Table 7 Percent of adult population without completed secondary education

\begin{tabular}{|c|c|c|c|c|c|c|}
\hline GEO/TIME & 2000 & 2009 & 2010 & 2011 & 2012 & 2013 \\
\hline European Union (28 countries) & & 28.0 & 27.3 & 26.6 & 25.8 & 24.8 \\
\hline Germany & 18.7 & 14.5 & 14.2 & 13.7 & 13.7 & 13.7 \\
\hline Nordrhein-Westfalen & 21.7 & 18.7 & 18.7 & 18.3 & 18.2 & 18.4 \\
\hline Düsseldorf & 23.3 & 19.1 & 19.2 & 18.6 & 18.9 & 19.6 \\
\hline Köln & 21.5 & 18.4 & 18.2 & 18.4 & 18.1 & 18.8 \\
\hline Münster & 20.5 & 17.2 & 16.7 & 16.3 & 16.5 & 16.0 \\
\hline Detmold & 20.5 & 17.3 & 17.2 & 16.9 & 16.5 & 16.6 \\
\hline Arnsberg & 21.0 & 20.4 & 20.6 & 19.8 & 19.6 & 19.0 \\
\hline Greece & 48.4 & 38.5 & 37.3 & 35.4 & 34.2 & 32.8 \\
\hline Eastern Macedonia \& Thrace & 62.1 & 51.0 & 50.2 & 50.3 & 51.7 & 51.3 \\
\hline Central Macedonia & 49.5 & 40.6 & 38.4 & 36.0 & 35.6 & 34.5 \\
\hline Western Macedonia & 59.8 & 47.9 & 46.3 & 44.4 & 45.3 & 42.8 \\
\hline Thessaly & 58.6 & 40.6 & 40.9 & 39.2 & 37.8 & 37.0 \\
\hline
\end{tabular}

European Commission, Regio dataset 


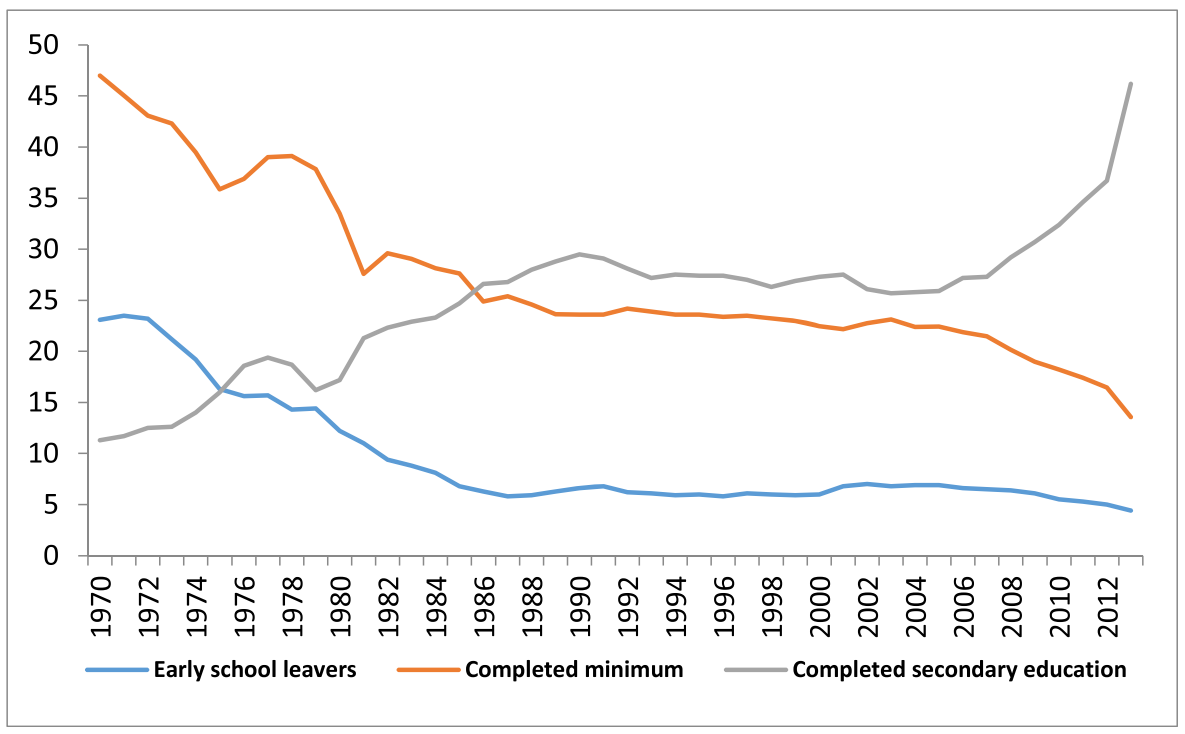

Fig. 9 Distribution of schooling levels in NRW

today that proportion is close to $40 \% .^{20}$ On the other side of the scale one finds that in 1970 almost one fourth did not even finish the minimum schooling with a degree and over $45 \%$ had finished only the minimum.

These numbers based on the German system are not directly comparable to those in Table 7 above, which is based on an international classification. However, a broad impression appears clearly that at the beginning of the 1970s the Land NRW was in an even worse position than the Greek average and close to the Northern Greek regions. A large part of the structural change that happened in NRW and in particular in the Ruhrgebiet was based on the radical improvement in the level of schooling of the local (young) population.

\subsection{Education and employment}

Employment rates vary greatly by the level of education. In most EU Member States (as in most OECD countries) persons with a higher level of education have a much higher propensity to be employed. This is the case in Greece as well, but the employment rates are much lower than elsewhere.

For example, the employment rates of persons with a completed tertiary education, i.e. those with a University degree, are usually around $80 \%$ in most EU countries. In Germany, this rate is now at an unusually high $88 \%$, but the EU average is still $82 \%$. In Greece the corresponding rate is only $68 \%$, which is one of the lowest in the EU and 20 points lower than the German rate. Though it is not possible to find data on employment rates by education at the regional level, this low value is most likely due to the extraordinary depth of the recession (Table 8).

\footnotetext{
${ }^{20}$ The 2013 data point might be somewhat distorted by the fact that this is the year with two cohorts in the 'Abitur' level as the duration of the cycle leading to this level was shortened from 13 to 12 years.
} 


\subsection{Neither in education nor employment}

A key indicator of the outlook for the young generation is the proportion of those who are neither in employment, education nor training (NEET). Here there are also striking differences between the countries. Already at the start of EMU the percentage of youth without a job and neither in education, nor in training was at about $17 \%$, on average for Greece, more than two times higher than the corresponding German value of 7.7\%.Within Germany the Ruhr area had a significantly higher proportion of NEETs, with an average for NRW of $8.70 \%$ and over $10 \%$ in Düsseldorf (Table 9).

But this value was only one half of the level for most Northern regions in Greece (e.g. $21.5 \%$ for Thrace). During the boom years the proportion of youth without job and not in education or training declined significantly throughout Greece, reaching $11.4 \%$ in 2008. But it then doubled until 2013 as the youth apparently did not chose to go into training or education when it became next to impossible to find a job. Thrace is again the region hardest hit and the NEETs ratio increased to $28 \%$.

The key conclusion to draw from this observation is twofold. On the one hand we see that an ever increasing number of young people in Greece are 'voting with their feet', i.e. migrating abroad in order to find employment opportunities (the German Migration Report for 2013 highlights this exodus of human capital).

Standard optimal currency area theory holds that in a currency area external shocks could be mitigated by internal factor mobility (the area being "optimal" if this happens on a large scale at little or no costs). But within the Eurozone cultural barriers and other factors limit labour mobility. Moreover, opportunities for mobility are is necessarily selective: only educated people will move. Given the cultural barriers mentioned, the scale of labour outward mobility from Greece has been clearly insufficient to provide a significant safety valve; unemployment has skyrocketed anyway.

If the level of education (both in quantity and quality terms) had been higher emigration might have been larger, providing more of a short term safety valve (as happened in the case of Ireland). Whether more labour mobility would have been in the long term interest of the country is difficult to determine.

Assuming that a recovery soon takes root in Greece, most of the high-skilled emigrants might eventually return to Greece, improving and further upgrading human capital with their experience gained abroad, strengthening the recovery. In this case, short-term mobility may prove a long-term advantage. But if the recession continues, or few return because they have taken root abroad; there is the risk that the country might have lost the best and brightest, who left behind a 'lost generation', unemployed or employed in jobs for which they have not studied and that hardly pay decent wages.

\section{Investment in innovation}

The EU has a target (or rather a benchmark) of 3\% of R\&D investment in GDP. This benchmark was originally established in 2000 in the framework of the Lisbon Strategy. It has since been kept in the context of the Europe 2020 strategy, which constitutes the current growth strategy for the EU. Germany on average just about reaches this target, but NRW does not as R\&D expenditure amounts to only about $2 \%$ of GDP. Within NRW there are considerable differences with Köln slightly above the German average, 
Table 8 Employment rates by educational attainment in Germany and Greece

\begin{tabular}{lll}
\hline & Tertiary education & Below secondary \\
\hline European Union (15 countries) & 82 & 46 \\
Germany & 88 & 53 \\
Greece & 68 & 39 \\
\hline
\end{tabular}

Eurostat data. Reference year is 2014

but Münster with a value of only $1 \%$, equal to about one third of the German average; see Table 10.

However, these regional differences pale when compared with the differences between Germany and Greece overall. The average for Greece is only one fifth of the average for Germany and Northern Greece is in general below the Greek average. Western Macedonia (where the lignite operations are) shows almost no R\&D expenditure (only $0.2 \%$ of GDP).

The huge differences in the rate of expenditure on R\&D do not seem to be the result of a lack of personnel as the differences in the availability of R\&D personnel appears to be minor, relative to the differences in expenditure. Table 11 below shows that about $2 \%$ of the German active population is in the R\&D sector. This percentage is somewhat lower in NRW, with the same regional variation as above (Köln is much more R\&D intensive than Münster).

The regional variations illustrated here have been very stable over time. There is no sign that R\&D spending is systematically increasing in the laggard regions of both countries.

In per capita terms the differences are even starker. With the average expenditure on R\&D for Germany over 900 Euros per capita (and 650 for NRW), it is 8 times higher than the averages for Greece and Northern Greece (125 and 80 Euros per capita,

Table 9 Percent of young population (15-24 years) not in employment, education nor training (NEET)

\begin{tabular}{llllllll}
\hline GEO/TIME & 2000 & 2008 & 2009 & 2010 & 2011 & 2012 & 2013 \\
\hline Germany & 7.7 & 8.4 & 8.8 & 8.3 & 7.5 & 7.1 & 6.3 \\
Nordrhein-Westfalen & 8.7 & 9.1 & 9.7 & 9.3 & 8.4 & 8.2 & 7.2 \\
Düsseldorf & 10.2 & 10.1 & 10.3 & 10.4 & 10.1 & 8.8 & 8.2 \\
Köln & 8.8 & 8.5 & 8.8 & 8.7 & 8.4 & 7.0 & 6.5 \\
Münster & 5.5 & 8.7 & 9.2 & 8.3 & 6.7 & 7.9 & 6.2 \\
Detmold & 7.6 & 8.6 & 9.0 & 8.6 & 7.5 & 7.4 & 6.2 \\
Arnsberg & 9.6 & 8.9 & 10.9 & 9.6 & 7.9 & 9.3 & 8.0 \\
Greece & 16.9 & 11.4 & 12.4 & 14.8 & 17.4 & 20.2 & 20.4 \\
Eastern Macedonia \& Thrace & 21.5 & 15.3 & 16.5 & 21.5 & 27.4 & 28.1 & 28.3 \\
Central Macedonia & 15.2 & 10.5 & 11.1 & 12.8 & 16.1 & 18.8 & 19.4 \\
Western Macedonia & 22.2 & 13.1 & 11.4 & 12.2 & 18.5 & 23.3 & 22.1 \\
Thessaly & 20.2 & 11.9 & 13.0 & 16.9 & 19.7 & 21.3 & 19.6 \\
\hline
\end{tabular}

European Commission, Regio dataset 
Table 10 R\&D expenditure as \% of regional GDP

\begin{tabular}{llll}
\hline Germany & 3.0 & Greece & 0.6 \\
\hline Nordrhein-Westfalen & 2.1 & Northern Greece & 0.5 \\
Düsseldorf & 1.9 & Eastern Macedonia \& Thrace & 0.5 \\
Köln & 3.2 & Central Macedonia & 0.6 \\
Münster & 1.1 & Western Macedonia & 0.2 \\
Detmold & 1.9 & Thessaly & 0.4 \\
Arnsberg & 1.6 & & \\
\hline
\end{tabular}

European Commission, Regio dataset. Reference year is 2014

respectively). The intra-regional variations show the same pattern as above: very little expenditure on $R \& D$ in the regions dominated by lignite mining and more in University cities, like Köln in Germany and Thessaloniki in northern Greece. ${ }^{21}$

The observation that $\mathrm{R} \& \mathrm{D}$ expenditure limitation is not due to the unavailability or shortage of university graduates is confirmed by the fact that there is today almost no difference in the proportion of the work force with tertiary education. This proportion is now about $28 \%$ on average for Germany as for Greece. University graduates are somewhat less numerous in NRW as in Northern Greece, amounting in both regions to about $25 \%$ of the working age population as shown in Table 12 below.

In both Germany and Greece the prevalence of academic qualification has increased over the last decades, but much more so in the latter, than in the former. In NRW the proportion of the working age population with a tertiary degree has increased by about 5 percentage points, but in Northern Greece the increase was about 10 percentage points. At the start of EMU an 'academic gap' existed between Germany and Greece. Two decades later this gap no longer exists.

R\&D spending is of course not the only way to foster innovation capacity. Corrado, Hulten and Sichel $(2005,2006)$ look at innovation in broader terms and identify several other elements fostering innovation, such as:i) software and computerized information, ii) scientific and non-scientific R\&D and iii) economic competencies. This arrangement has also been called 'intangible capital' and comprises more elements than only investment in physical capital and R\&D proper; see also Roth (2010), and Roth and Thun (2010). Figures 10 and 11 show the single dimensions of economic competencies in the EU15 in comparison to the Europe 2020 indicator of R\&D expenditure.

In all 15 European economies investment in economic competencies in general exceeds in importance R\&D. Greece stands out as the country investing less in intangible capital and thus innovation broadly defined. Thus an indicator purely based on manufacturing seems to be flawed for those economies, which are strongly based on the service sector and with SMEs being the corporate backbone.

The key issue for a laggard in terms of innovation would thus seem to be not simply increasing investment in $\mathrm{R} \& \mathrm{D}$, but to create an environment which

\footnotetext{
${ }^{21}$ Münster is a negative outlier within NRW, with its expenditure on R\&D of only 300 euros despite its tradition as a university city.
} 
Table 11 R\&D personnel as \% of active population

\begin{tabular}{lllr}
\hline Germany & 1.97 & Greece & 1.41 \\
\hline Nordrhein-Westfalen & 1.63 & Northern Greece & 1.47 \\
Düsseldorf & 1.32 & Eastern Macedonia \& Thrace & 1.37 \\
Köln & 2.61 & Central Macedonia & 1.44 \\
Münster & 1.04 & Western Macedonia & 1.25 \\
Detmold & 1.54 & Thessaly & 1.74 \\
Arnsberg & 1.35 & & \\
\hline
\end{tabular}

European Commission, Regio dataset. Reference year is 2014

fosters a high rate of investment in intangible capital. This applies in particular to economies dominated by services since R\&D seems to be particularly intensive in the manufacturing sector.

One reason for the absence of investment in intangible capital in Greece might the fact that the middle level in terms of education is missing. Combining the data on the working age population with a tertiary education with the data on those without a completed secondary education illustrates the proportion of the work force which is in the middle. Table 13 below shows the 'middle class' in terms of education, i.e. those without a university degree, but having completed at least secondary education.

It is apparent that in Germany this 'middle class' dominates, with between 50 and $60 \%$ of the work force, whereas in Greece it is much less important amounting to only between 30 and $38 \%$.

The financing of innovation is another thorny issue for Greece. The ongoing fiscal consolidation is unlikely to allow any serious increase of the financial resources made available by the state to support business innovation. On the other hand, companies, hit by a chronic lack of liquidity and shortages even in working capital, are also unlikely to engage in front-line high-tech investments in the near future. The remaining options are the European Structural Funds and the participation of Greek companies in European investment platforms, such as the Jessica framework, the recent Juncker Plan for European investments and other schemes of private and public financial partnerships.

Table 12 Working age population with tertiary education

\begin{tabular}{lllr}
\hline Germany & 28.5 & Greece & 27.4 \\
\hline Nordrhein-Westfalen & 25.0 & Northern Greece & 24.8 \\
Düsseldorf & 24.4 & Eastern Macedonia \& Thrace & 19.5 \\
Köln & 29.1 & Central Macedonia & 27.1 \\
Münster & 24.6 & Western Macedonia & 20.1 \\
Detmold & 23.1 & Thessaly & 25.1 \\
Arnsberg & 21.9 & & \\
\hline
\end{tabular}

Eurostat. Reference year is 2014 


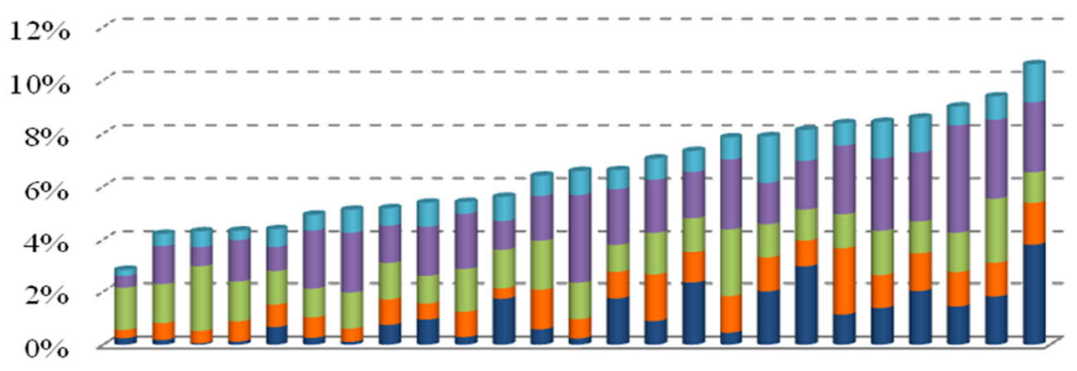

gi lv cy lt es pt mt it ie pl lu sk ee at cz dehudk fi si nl fi uk be se

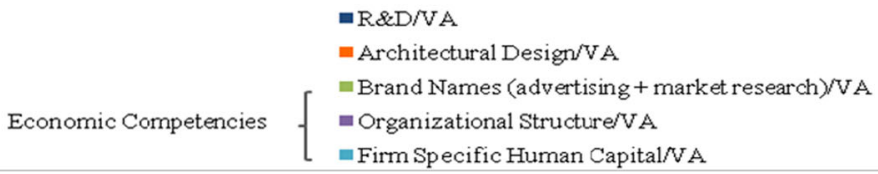

Fig. 10 Investment in Intangible Capital by Businesses in the EU15 Compared to R\&D. Source: INNODRIVE data

\section{The importance of good governance}

A key element in any structural reform effort is the quality of governance of the local administration and the public sector in general (Belke 2013). Gros and Roth (2012) also show that R\&D efforts depend not only on economic variables, but also strongly on the quality of the public administration. That the quality of the state administration has an important impact on the performance of the school system should be almost selfevident. Gros (2006) shows that, indeed, the quality of schools as measured by the PISA results of high school students depends less on the amount spent on education and more on the absence of corruption.

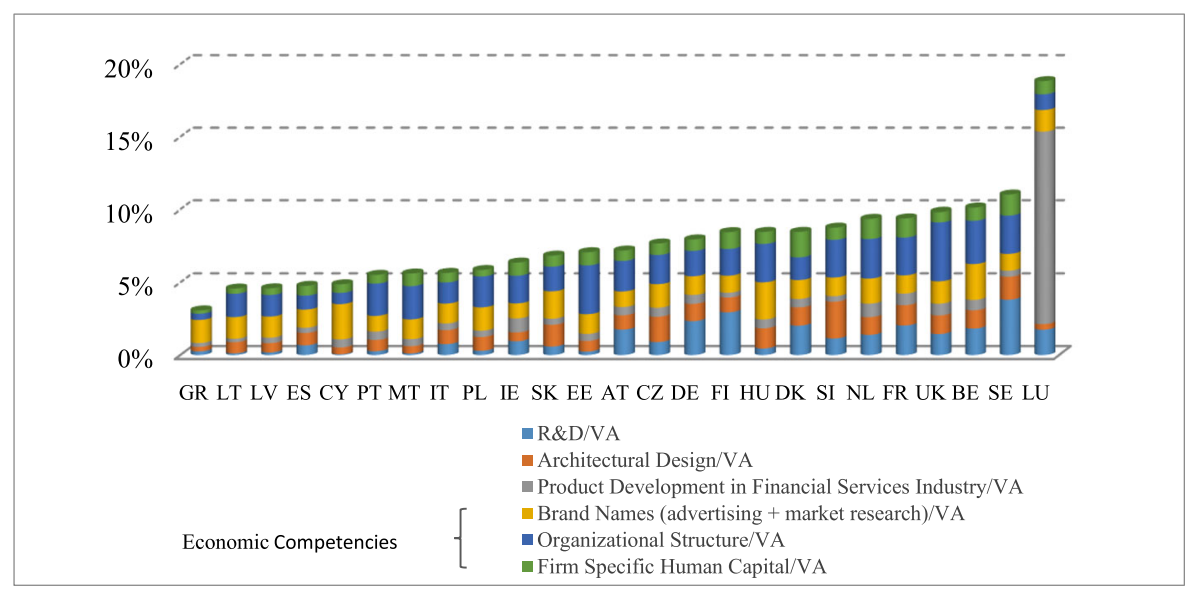

Fig. 11 Investment in new intangible capital by businesses in the EU-25 compared to R\&D (1995-2005) Source: Author's own estimation with INNODRIVE data. (Excluding product development in financial services industry) 
Table 13 The 'middle class' in terms of education

\begin{tabular}{lllr}
\hline Germany & 57.8 & Greece & 39.8 \\
\hline Nordrhein-Westfalen & 56.6 & & \\
Düsseldorf & 56.0 & Eastern Macedonia \& Thrace & 29.2 \\
Köln & 52.1 & Central Macedonia & 38.4 \\
Münster & 59.4 & Western Macedonia & 37.1 \\
Detmold & 60.3 & Thessaly & 37.9 \\
Arnsberg & 59.1 & & \\
\hline
\end{tabular}

Eurostat

Very recently some data on the quality of governance has been published which allows one to measure this aspect at the regional level. ${ }^{22}$ The results at the national level confirm those obtained from other sources, such as the indicators from the World Bank, or the World Economic Forum. However, one finds considerable diversity within Germany, but much less within Greece.

To illustrate, the German average ranks with a value of +0.9 in sixty-second position among all the 200 plus EU regions and NRW ranks with a value of 0.76 at rank 76 . But other German Länder display a much better result. By contrast, all the Greek regions have a value close to -1.0 and are clustered between 195-199 positions.

Thus, there is a wide gap in terms of the quality of governance between Germany and Greece and also between NRW and Northern Greece. This gap is likely to have a profound impact on regional economies as well since inadequate governance impedes human capital formation and investment in intangible capital. ${ }^{23}$

\section{Conclusions}

According to our analysis the conclusions of Gros (2006) still stand today:

The basic message suggested by this simple result is at the same time simple, and somewhat discouraging. If general government efficiency is the main determinant of educational achievement, it implies that partial reforms within the education sector are unlikely to improve student achievements fundamentally. Many aspects of public administration need to be overhauled and improved if one wants to improve educational outcomes as measured by the PISA results. This is likely to require time and a general consensus (as it was the case when reforming the Ruhrgebiet).

Partial reforms that improve, for example, the distribution of resources - by introducing more competition and greater transparency - can be designed and

\footnotetext{
$\overline{22}$ http://ec.europa.eu/regional_policy/sources/docgener/work/2012_02_governance.pdf

${ }^{23}$ A list of priorities for regional policy that could guide the design and implementation of the European Structural Funds can be found in https://www.makro.wiwi.uni-due.de/fileadmin/fileupload/VWLMAKRO/Presse/2015/Greece_Ruhr-Mercator.pdf, sections 0.1 and 7.2. There, we are dealing with structural funds as a resource of greater financial autonomy of Greek regions and defining a new growth agenda for Greek regions.
} 
implemented in a rather short time and should have a positive impact. But they have to be implemented by the existing public administration, whose quality cannot be improved overnight. Hence even the best designed reforms are likely to have only a limited impact, as long as the overall quality of public administration does not improve. This should be the ultimate aim of all reforms, but it is more difficult to achieve as it requires a 'long march' through the institutions.

A low quality of local institutions does not only lead to worse educational outcomes (as measured, for example, by the PISA results) but also to overall productivity and attractiveness for FDI. This introduces another aspect which differentiates the experience of NRW and that of Greece: in Greece the many reforms formally adopted under the pressure of the Troika seemed to have had little impact on the ground. By contrast, the reforms needed in NRW were implemented by a local administration which was of much higher quality, thus making success much more likely.

Acknowledgements This article was published open access with the support of King's College London. We gratefully acknowledge funding by the Mercator Foundation, valuable input by Jens Bastian, Athens, and support and comments by Aspa Kyriaki, Thessaloniki, and Georgios Papandreou, Athens.

Open Access This article is distributed under the terms of the Creative Commons Attribution 4.0 International License (http://creativecommons.org/licenses/by/4.0/), which permits unrestricted use, distribution, and reproduction in any medium, provided you give appropriate credit to the original author(s) and the source, provide a link to the Creative Commons license, and indicate if changes were made.

\section{References}

Alexiou C, Pitelis C (2003) On capital shortages and European unemployment: a panel data investigation. Journal of Post Keynesian Economics 25(4):613-640

Arvanitidis N (1998) Northern Greece's industrial minerals: production and environmental technology developments. J Geochem Explor 62:217-227

Barslund, M. and D. Gros, 2013, "Unemployment is the scourge, not youth unemployment per se: The misguided policy preoccupation with youth. CEPS Policy Brief, Centre for European Policy Studies (CEPS), web: http://www.ceps.eu/book/unemployment-scourge-not-youth-unemployment-se-misguidedpolicy-preoccupation-youth. Accessed 1 Jan 2017

Bauer, T. et al., 2011, "Den Wandel gestalten - Anreize für mehr Kooperationen im Ruhrgebiet. Endbericht, Projekt im Auftrag der RAG-Stiftung, Rheinisch-Westfälisches Institut für Wirtschaftsforschung (RWI), Essen

Belke, A., 2013, "Debt mutualisation in the ongoing eurozone crisis - A tale of the 'North' and the 'South'. The New Palgrave Dictionary of Economics, Online Edition, Eds. Steven N. Durlauf and Lawrence E. Blume, Palgrave Macmillan, Houndmills, Basingstoke, web: http:/www.dictionaryofeconomics. com/article?id=pde2013_D000273. Accessed 1 Jan 2017

Belke A, Dreger C (2011) Das zweite Rettungspaket für Griechenland. Wirtschaftsdienst 91(9):601-607

Belke A, Heine J (2002) Der Einfluss von Agglomeration auf die Synchronisation regionaler europäischer Konjunkturzyklen. Zeitschrift für Agrarpolitik und Landwirtschaft80, p 305ff

Belke A, Heine J (2006) On the endogeneity of an exogenous OCA-criterion: specialisation and the correlation of regional Business Cycles in Europe. Empirica 34(1):15-47

Charalampides G, Vatalis K, Platias S, Karayannis V (2014) The contribution of industrial minerals to a sustainable recovery of the Greek economy. Procedia Economics and Finance 14:128-136

Christodoulakis N (2014) Underinvestment and unemployment: the double hazard in the euro area. Bank of Greece, Working Paper, Athens 
Christodoulakis N, Petrakos G (2000) Greece and the Balkans: the challenge of integration. In: Petrakos G, Maier G, Gorzelak G (eds) Integration and transition in Europe: the economic geography of interaction. Routledge, London, pp 269-294

Christodoulakis, N. and V. Sarantides, 2015, "External imbalances in the Eurozone and the role of Foreign Direct Investment". (Forthcoming)

Corrado, C., Ch. Hulten and D. Sichel (eds), 2005, Measuring capital in the new economy, NBER edition, http://www.nber.org/books/corr05-1. Accessed 1 Jan 2017

Roth Felix, 2010, "Measuring innovation - intangible capital in the EU. in: K. Blind et al. (2010), drivers and impediments for innovation in Europe. Intereconomics 45, pp. 273-277

Gros, D., 2006. Efficient education strategies in Europe: what can we learn from an international comparison? VoxEU.org, available at: http://www.voxeu.org/article/education-strategies-europe. Accessed 1 Jan 2017

Gros D. and F. Roth, 2012, "The Europe 2020 strategy: can it maintain the EU's competitiveness in the world?. http://www.ceps.eu/book/europe-2020-strategy-can-it-maintain-eu\%E2\%80\%99scompetitiveness-world. Accessed 1 Jan 2017

Karanassou M, Sala H, Salvador PF (2008) Capital accumulation and unemployment: new insights on the Nordic experience. Camb J Econ 32(6):977-1001

Komninos N (2008) Intelligent cities and globalisation of innovation networks. Routledge, London

Palaskas T, Tsampra M, Stoforos C (2013) Regional business competitiveness: medium and low-technology production systems in northern Greece. European Research Studies XVI (1):20-28

Roth, F. and A. E. Thun, 2010, "Does intangible capital affect economic growth?. CEPS Working Documents No 335 Centre for European Policy Studies, Brussels, September

Rowthorn R (1999a) Unemployment, Capital-Labour Substitution and Economic Growth. In: IMF Working Paper WP/99/43. International Monetary Fund, Washington/DC

Rowthorn R (1999b) Unemployment, wage bargaining and capital-labour substitution. Camb J Econ 23:413425

Tsipouri L (1998) Promoting coordination at regional level: the case of northern Greece. In: Storper M, Thomadakis SB, Tsipouri LJ (eds) Latecomers in the global economy. Routledge, London, pp 275-298

Publisher's note Springer Nature remains neutral with regard to jurisdictional claims in published maps and institutional affiliations. 